\title{
Phase I trial of capecitabine plus everolimus (RAD001) in patients with previously treated metastatic gastric cancer
}

\author{
Taekyu Lim • Jeeyun Lee $\cdot$ Duk Joo Lee $\cdot$ Ha Yeon Lee $\cdot$ Boram Han $\cdot$ Kyung Kee Baek \\ Hee Kyung Ahn · Su Jin Lee · Se Hoon Park · Joon Oh Park • Young Suk Park • \\ Ho Yeong Lim • Kyoung-Mee Kim • Won Ki Kang
}

Received: 22 December 2010/Accepted: 14 April 2011/Published online: 28 April 2011

(C) The Author(s) 2011. This article is published with open access at Springerlink.com

\begin{abstract}
Purpose Everolimus is a novel inhibitor of the mammalian target of rapamycin pathway, which is aberrantly activated in cancer cell. We conducted a phase I study of capecitabine plus everolimus (RAD001) in refractory gastric cancer patients.

Methods Patients with metastatic gastric cancer and progression after prior chemotherapy were eligible. Four dose levels were planned as follows: Level $1,5 \mathrm{mg}$ bid/day of everolimus (D1-D21) and $500 \mathrm{mg} / \mathrm{m}^{2}$ bid/day of capecitabine (D1-14); Level 2, $5 \mathrm{mg}$ bid/day of everolimus (D1-D21) and $750 \mathrm{mg} / \mathrm{m}^{2}$ bid/day of capecitabine (D1-14); Level 3, $5 \mathrm{mg}$ bid/day of everolimus (D1-D21) and $1000 \mathrm{mg} / \mathrm{m}^{2} \mathrm{bid} /$ day of capecitabine (D1-14); and Level 4, $10 \mathrm{mg} \mathrm{bid} /$ day of everolimus (D1-D21) and $1000 \mathrm{mg} / \mathrm{m}^{2}$ bid/day of capecitabine (D1-14). Treatment was repeated every 3 weeks until disease progression, patient refusal, or any serious adverse event.

Results Fifteen patients were enrolled in this study between November 2009 and April 2010. Fifteen patients were enrolled (median age, 50 years; men, 9). Six patients had received two previous chemotherapy regimens; six patients had three previous chemotherapy regimens before
\end{abstract}

T. Lim · J. Lee $(\bowtie) \cdot$ D. J. Lee $\cdot$ H. Y. Lee $\cdot$ B. Han

K. K. Baek - H. K. Ahn - S. J. Lee - S. H. Park ·

J. O. Park · Y. S. Park - H. Y. Lim - W. K. Kang

Division of Hematology-Oncology, Department of Medicine,

Samsung Medical Center Sungkyunkwan,

University School of Medicine, 50 Irwon-dong,

Gangnam-gu, Seoul, Korea

e-mail: jyunlee@ skku.edu

K.-M. Kim

Department of Pathology, Samsung Medical Center,

Sungkyunkwan University School of Medicine, Seoul, Korea the study treatment. Thus, the majority of patients were heavily pretreated. The dose-limiting toxicities were grade 3 infection, grade 3 mucositis, and grade 3 hyperglycemia and hyponatremia. After a median follow-up duration of 5.6 months (range, 2.3-8.1 months), median PFS was 1.8 months (95\% CI, 0.8-2.8 months). The maximum best change observed was a $28.7 \%$ decrease in sum of longest diameters when compared with baseline.

Conclusions The combination of capecitabine and everolimus showed satisfactory toxicity profile and modest clinical benefit in patients with refractory gastric cancer. The recommended dose of capecitabine and everolimus was $650 \mathrm{mg} / \mathrm{m}^{2}$ twice daily and $5 \mathrm{mg}$ twice daily, respectively.

Keywords Gastric cancer - Everolimus - Capecitabine

\section{Introduction}

Gastric cancer is the most common cancer type and the major cause of cancer death in Korea [1]. The role of cytotoxic chemotherapy has been extensively investigated in metastatic gastric cancer in various settings. Despite this rigorous endeavor, the response rate is still below $50 \%$ to first-line chemotherapy and the duration of response is as short as a few months [2]. As was previously reported, limited clinical trials have been conducted as salvage treatment after failure to first-line chemotherapy [3-5]. Our retrospective analysis indicated that an overall response rate was only $16 \%$ (95\% CI, 13-19\%) to second-line chemotherapy and overall survival calculated from the date of second-line chemotherapy was only 6.7 months $(95 \%$ CI, 5.8-7.5 months) [6]. Given the poor clinical outcome, there is an urgent need for novel treatment in gastric cancer patients, especially in salvage setting. 
One of the promising candidates for novel targeted agent is everolimus, an oral inhibitor of the mammalian target of rapamycin (mTOR). Recently, phase II study of everolimus monotherapy demonstrated promising disease control rate of $56.0 \%$ (95\% CI, 41.3-70.0\%) in second- or third-line setting [7]. mTOR, a serine/threonine kinase, is involved in the control of translation in response to insulin and various endogenous growth factors via the PI3 K/Akt pathway and cellular nutrient and is thought to play a central role in regulating cell growth, cell cycle progression, and tumorigenesis [8, 9]. Previous studies including ours have demonstrated that mTOR is activated in gastric cancer about $60 \%$ and mTOR activation is strongly correlated with poor prognosis [10].

A few recent phase III trials and meta-analysis have demonstrated that survival with capecitabine-based regimens compares favorably with that of 5-fluorouracil-based regimens as first-line therapy for patients with advanced gastric cancer [11-13]. Bu et al. suggested that the inhibitors of mTOR plus 5-FU may have potential anticancer activity and that downregulation of AP-1 and NF-kappa B transcription activity might result in a senescence-like growth arrest [14]. On the basis of these data, we hypothesized that co-administration of an mTOR inhibitor with capecitabine enhances anticancer effects in patients with advanced gastric cancer. In this study, we conducted a phase I study of capecitabine plus everolimus to determine the maximum-tolerated dose (MTD) and the dose-limiting toxicity (DLT) in refractory metastatic gastric cancer patients.

\section{Patients and methods}

A prospective, single center, open-label study with dose escalation was conducted to evaluate the efficacy and safety of capecitabine plus everolimus in patients with metastatic gastric cancer who have failed previous chemotherapy.

\section{Patient eligibility}

Eligibility criteria for study entry were as follows: (1) histologically or cytologically confirmed advanced unresectable or metastatic or recurred gastric adenocarcinoma, (2) age greater than 18 years, (3) at least one measurable lesion according to the RECIST (response evaluation criteria in solid tumors) 1.0 criteria, (4) ECOG (Eastern Cooperative Oncology Group) performance status 0-2, (5) no evidence of progression and normal neurologic function within 8 weeks in patients with metastatic tumors of central nervous system, (6) patients who failed at least two cytotoxic chemotherapy regimens (adjuvant chemotherapy administered within
1 year from the study entry date was counted as one regimen), (7) adequate organ function; hematologic parameters (hemoglobin $\geq 9.0 \mathrm{~g} / \mathrm{dl}$, absolute neutrophil count (ANC) $\geq 1,500 / \mathrm{mm}^{3}$, platelet count $\geq 100,000 / \mathrm{mm}^{3}$ ), renal function (serum creatinine $<1.5 \mathrm{mg} / \mathrm{dl}$ ), and hepatic function (aspartate aminotransferase, alanine aminotransferase $<2.5 \times$ upper limits of normal, total bilirubin $<3 \times$ upper limit of normal) and serum calcium $>9 \mathrm{mg} / \mathrm{dl}$. The exclusion criteria were as follows: (1) patients treated with major surgery or radiotherapy within 4 week before clinical trial, (2) patients having hypersensitivity to everolimus or capecitabine, (3) patients having diabetes mellitus treated with oral hypoglycemic agents or insulin injection, (4) patients with confirmed leptomeningeal carcinomatosis (cytologically confirmed or neurologic symptoms with evidence of CT or MRI), (5) grade 2 or more cardiac dysfunction based on National Cancer Institute Common Terminology Criteria for Adverse Events (NCI CTCAE, version 3.0), (6) life expectancy less than 3 months, (7) active gastrointestinal bleeding which needed transfusion, (8) severe comorbidities such as active infection and severe cardiopulmonary dysfunction, (9) patients requiring long-term immunotherapy such as corticosteroid or other immunosuppressants, (10) previous or concurrent other malignancies except treated basal cell or squamous carcinoma of skin or treated cancer from which the patient had been continuously disease-free for more than 3 years. Women could not be pregnant or could not breast-feed and women of childbearing potential and sexually active men were strongly advised to use an accepted and effective method of contraception. All patients provided written informed consent. The protocol and the informed consent form were approved by the Institutional Review Board.

\section{Administration and dose escalation}

Three patients were accrued to each dose level. If none of the three patients experienced DLT, the dose was increased in a subsequent group of three patients. If DLT occurred in 1 of the 3 initial patients at a particular dose level, then 3 additional patients were treated at the same dose level for a total of six patients. If DLT developed in 2 of six patients, then enrollment was stopped at this dose level, which was defined as the MTD. The preceding dose level (one level lower) was designated as the recommended dose (RD) for the phase II study. If two of the first three patients experienced DLT, then dose escalation was planned to be stopped and de-escalated to intermediate dose (Level 1A).

Dose escalation scheme is outlined in Table 1. Four dose levels were planned as follows: Level 1, $5 \mathrm{mg}$ bid/day of everolimus (D1-D21) and $500 \mathrm{mg} / \mathrm{m}^{2} \mathrm{bid} / \mathrm{day}$ of capecitabine (D1-14); Level 2, $5 \mathrm{mg}$ bid/day of everolimus (D1-D21) and $750 \mathrm{mg} / \mathrm{m}^{2} \mathrm{bid} /$ day of capecitabine (D1-14); 
Table 1 Dose escalation scheme

\begin{tabular}{llc}
\hline Dose level & $\begin{array}{l}\text { RAD001 } \\
(\mathrm{mg}, \mathrm{q} 12 \mathrm{~h} \text {, daily })\end{array}$ & $\begin{array}{l}\text { Capecitabine }\left(\mathrm{mg} / \mathrm{m}^{2},\right. \\
\mathrm{q} 12 \mathrm{~h} \text {, days } 1-14)\end{array}$ \\
\hline Level -1 & 2.5 & 500 \\
Level 1 & 5 & 500 \\
Level 1A & 5 & 650 \\
Level 2 & 5 & 750 \\
Level 3 & 5 & 1,000 \\
Level 4 & 10 & 1,000 \\
\hline
\end{tabular}

Level 3, $5 \mathrm{mg}$ bid/day of everolimus (D1-D21) and $1,000 \mathrm{mg} / \mathrm{m}^{2} \mathrm{bid} /$ day of capecitabine (D1-14); and Level 4, $10 \mathrm{mg} \mathrm{bid} /$ day of everolimus (D1-D21) and $1,000 \mathrm{mg} / \mathrm{m}^{2}$ bid/day of capecitabine (D1-14). Treatment was repeated every 3 weeks until disease progression, patient refusal, or any serious adverse event. If Level 1 is well tolerated (no DLT) and level 2 is too toxic ( $\geq 2$ patients suffer DLT in a cohort of 6 patients), then Level 1A will be tested. (Level 1A: everolimus $5 \mathrm{mg}$ bid, capecitabine $650 \mathrm{mg} / \mathrm{m}^{2}$ bid). Treatment was administered when ANC $\geq 1,500 \mathrm{~mm}^{3}$, platelets $\geq 75,000 \mathrm{~mm}^{3}$, and non-hematologic toxicities resolved to grade $<2$. Dose modification was primarily for grade 3-4 toxicities or for grade 2 toxicities deemed intolerable due to persistence or disease progression. For toxicities potentially attributable to either drug, the dose of both drugs was reduced by $25 \%$ in capecitabine and $50 \%$ in everolimus per toxicity occurrence; when toxicity could be attributed primarily to only one agent, only that drug was modified (e.g., hand-foot syndrome attributed to capecitabine). Modifications were based on the most severe toxicity.

\section{Dose-limiting toxicity}

DLT was defined as any of following events observed during cycle 1 of therapy: any grade 3 non-hematologic toxicity, grade 4 febrile neutropenia, grade 4 anemia or thrombocytopenia, grade 2 hemorrhage with grade 3 thrombocytopenia, failure to recover neutrophils $(1,500 /$ $\mathrm{mm}^{3}$ ) by day 7. Safety was assessed every week for the first cycle of treatment. Adverse events were evaluated according to the NCI CTCAE, version 3.0. All adverse events were evaluated until 21 days after the last dose of study drug.

\section{Immunohistochemistry}

Antibodies used were anti-phospho-Akt immunohistochemistry-specific rabbit IgG antibody (Ab Catalog No \#3787, Cell Signalings, USA) (1:100).
Response evaluation

Pretreatment evaluations included history taking and physical examination, assessment of performance status, complete blood count (CBC), and hepatic and renal function tests. Serum triglycerides and a full lipid profile were obtained at baseline. Radiological (chest X-ray, computed tomography) studies to assess response were performed after every 2 cycles of therapy until disease progression. Response definitions were according to Response Evaluation Criteria in Solid Tumors (RECIST) 1.0 [15]. Progression-free survival (PFS) was defined as the time from the date of treatment initiation to the date of the first documentation of disease progression (by radiologically or clinically) or death. Patients with progression-free status were censored at the last date verifying survival. Overall survival (OS) was defined as the time from the date of starting treatment to the date of death. Surviving patients were censored at the last confirmation date of survival. The Kaplan-Meier method was used to estimate the median values of time-to-event variables, such as overall survival (OS) and progression-free survival (PFS).

\section{Results}

\section{Patient characteristics}

Fifteen patients were enrolled in this study between November 2009 and April 2010 at Samsung Medical Center. The patient characteristics are shown in Table 2. Nine patients were men, and the median age was 50 (range, 37-72) years. Eight patients (53.3\%) had prior gastrectomy (curative, $n=4$; palliative, $n=4$ ), and four patients who received curative gastrectomy had received adjuvant concurrent chemoradiotherapy. Six patients had received two previous cytotoxic chemotherapy regimens, and six patients had three previous chemotherapy regimens before the study treatment. Thus, majority of patients were heavily pretreated.

\section{DLT and MTD}

Major adverse events occurring during the first cycle at each dose level are shown in Table 3. Grade 3 infection (Fournier's gangrene) occurred in one of the three patients at dose Level 1; therefore, additional three patients were enrolled to confirm tolerability. There were no additional DLTs observed at dose Level 1 in cohort of six patients. Subsequently, dose was escalated to Level 2. At Level 2, grade 3 hyperglycemia and grade 3 hyponatremia concurrently developed in one patient. Three additional patients were enrolled. Grade 3 mucositis, grade 3 thrombocytopenia, 
Table 2 Patient characteristics $(N=15)$

\begin{tabular}{|c|c|}
\hline Characteristics & No. of patients (\%) \\
\hline \multicolumn{2}{|l|}{ Sex } \\
\hline Male & $9(60.0)$ \\
\hline Female & $6(40.0)$ \\
\hline \multicolumn{2}{|l|}{ Age } \\
\hline Median age, years (range) & $50(37-72)$ \\
\hline \multicolumn{2}{|l|}{ ECOG performance status } \\
\hline 0 & $1(6.7)$ \\
\hline 1 & 13 (86.6) \\
\hline 2 & $1(6.7)$ \\
\hline \multicolumn{2}{|l|}{ No. of prior chemotherapy } \\
\hline \multicolumn{2}{|l|}{ Palliative } \\
\hline 1 & $1(6.7)$ \\
\hline 2 & $6(40.0)$ \\
\hline 3 & $6(40.0)$ \\
\hline$\geq 4$ & $2(13.3)$ \\
\hline \multicolumn{2}{|l|}{ Site of metastasis } \\
\hline Liver & 7 (46.7) \\
\hline Lung & $4(26.7)$ \\
\hline Peritoneum & $5(33.3)$ \\
\hline Intraabdominal lymph node & $9(60.0)$ \\
\hline Ovary/others & $4(26.7) / 3(20.0)$ \\
\hline \multicolumn{2}{|l|}{ No. of metastasis sites } \\
\hline 1 & $3(20.0)$ \\
\hline 2 & 7 (46.6) \\
\hline 3 & $4(26.7)$ \\
\hline 4 & $1(6.7)$ \\
\hline
\end{tabular}

ECOG Eastern Cooperative Oncology Group

grade 3 hyperglycemia/hyponatremia (concomitantly in one patient), and grade 3 hypophosphatemia occurred as DLTs. As a consequence, dose Level 2 was considered intolerable, and doses were de-escalated to the preplanned dose Level 1A (everolimus $5 \mathrm{mg}$ bid, capecitabine $650 \mathrm{mg} / \mathrm{m}^{2} \mathrm{bid}$ ). There was no DLT in the 3 patient cohort at dose Level 1A. Based on the results, we concluded that the MTD of this combination regimen was dose Level 2. Grade 3/4 adverse events in all cycles are shown in Table 4. Most common severe toxicity was grade 3 mucositis $(n=5)$. Grade 4 toxicities did not occur in all cycles. There was no grade 3 hand-foot syndrome or diarrhea. Incidence of radiologic interstitial pneumonia was not documented. There were no treatment-related mortalities observed in this trial.

\section{Efficacy}

A total of $43++$ cycles of chemotherapy were administered with median of 2 cycles (range 1-10+). All patients who received at least 1 dose of study treatment were considered evaluable for toxicity and response. Objective tumor responses at each dose level are provided in Table 5. Although there were six patients with stable disease resulting in disease control rate of $40.0 \%$ (95\% CI, 16.6-67.7\%), none achieved complete or partial response. After a median follow-up duration of 5.6 months (range, 2.3-8.1 months), median PFS was 1.8 months (95\% CI, 0.8-2.8 months) (Fig. 1). The maximum best change observed was a $28.7 \%$ decrease in sum of longest diameters when compared with baseline (Fig. 2). Of note, remaining three patients who did not develop DLTs in dose Level 2 continue to receive capecitabine and everolimus and maintained stable disease.

Immunohistochemistry analysis

Of the 13 cases evaluated, $15.4 \%$ ( 2 of 13 ) were positive for phosphor-Akt (Fig. 3). All two patients with phosphorAkt (+) had stable disease for 2.8 and 5.6 months, respectively, after capecitabine and everolimus combination treatment. Due to the limited number of patients, there was no significant correlation between clinical response and phosphor-Akt status in this series $(P=0.143)$.

\section{Discussion}

We demonstrated that combination treatment of capecitabine and everolimus has tolerable safety profile in metastatic gastric cancer patients. Based on our results, everolimus $5 \mathrm{mg}$ twice daily continuously can be safely added to capecitabine $650 \mathrm{mg} / \mathrm{m}^{2}$ twice daily D1-14 every 3 weeks in gastric cancer. DLTs observed in this trial were grade 3 infection (Fournier's gangrene), grade 3 mucositis, grade 3 thrombocytopenia, grade 3 hypophosphatemia, and grade 3 hyperglycemia/hyponatremia (concomitantly in one patient). The combination of capecitabine and everolimus was conveniently administered in an outpatient setting and very well tolerated. The most commonly observed grade 3 or greater toxicity was mucositis $(33.3 \%$ of all patients) which is concordant with previous study [16-18]. Furthermore, significant hematological toxicities requiring active interventions were not commonly observed as previously reported [16-18]. Frequently occurring adverse events related to everolimus were stomatitis/oral mucositis, fatigue, anorexia, hyperglycemia, hyperlipidemia, elevated liver enzymes, diarrhea, and hypophosphatemia [19-23]. In our study, hematologic abnormalities were uncommon with only four patients with grade 1-3 thrombocytopenia. There were no cases of neutropenia. Most toxicities were tolerable grade $1-2$ and readily manageable. There was no treatmentrelated mortality.

This combination regimen showed promising clinical activity. Although there were no patients with complete or 
Table 3 Adverse events during the first cycle

\begin{tabular}{|c|c|c|c|c|c|c|c|c|c|c|c|c|}
\hline & \multicolumn{4}{|c|}{ Dose Level $1(n=6)$} & \multicolumn{4}{|c|}{ Dose Level $2(n=6)$} & \multicolumn{4}{|c|}{ Dose Level 1A $(n=3)$} \\
\hline & \multicolumn{4}{|c|}{ Grade } & \multicolumn{4}{|c|}{ Grade } & \multicolumn{4}{|c|}{ Grade } \\
\hline & 1 & 2 & 3 & 4 & 1 & 2 & 3 & 4 & 1 & 2 & 3 & 4 \\
\hline \multicolumn{13}{|l|}{ Hematological } \\
\hline \multicolumn{13}{|l|}{ Anemia } \\
\hline Thrombocytopenia & 1 & 1 & & & & & 1 & & & & & \\
\hline \multicolumn{13}{|l|}{ Neutropenia } \\
\hline \multicolumn{13}{|l|}{ Leukopenia } \\
\hline \multicolumn{13}{|l|}{ Non-hematological } \\
\hline Anorexia & 3 & & & & & 1 & & & & & & \\
\hline Insomnia & & 1 & & & & 1 & & & & & & \\
\hline Dyspepsia & 1 & & & & 1 & & & & & & & \\
\hline Nausea & & & & & & & & & 2 & & & \\
\hline \multicolumn{13}{|l|}{ Vomiting } \\
\hline \multicolumn{13}{|l|}{ Constipation } \\
\hline \multicolumn{13}{|l|}{ Fatigue } \\
\hline \multicolumn{13}{|l|}{ Diarrhea } \\
\hline Mucositis & 1 & 2 & & & & & 1 & & 2 & & & \\
\hline Rash & & & & & 1 & & & & & & & \\
\hline Pruritus & 1 & & & & 1 & & & & 1 & & & \\
\hline \multicolumn{13}{|l|}{ Sensory neuropathy } \\
\hline \multicolumn{13}{|l|}{ Hand-foot syndrome } \\
\hline \multicolumn{13}{|l|}{ Febrile neutropenia } \\
\hline Headache & & 1 & & & 1 & & & & & & & \\
\hline AST/ALT & & $/ 1$ & & & & & & & & & & \\
\hline \multicolumn{13}{|l|}{ Hyperbilirubinemia } \\
\hline \multicolumn{13}{|l|}{ Hypercholesterolemia } \\
\hline Hypertriglyceridemia & 1 & & & & & & & & & & & \\
\hline Hyperglycemia & & & & & & & 1 & & & & & \\
\hline Hyponatremia & & & & & & & 1 & & & & & \\
\hline Hypokalemia & & 1 & & & & & & & & & & \\
\hline Hypophosphatemia & & 1 & & & & & 1 & & & & & \\
\hline Hypocalcemia & & & & & & 1 & & & & & & \\
\hline Proteinuria & & 1 & & & & 1 & & & & & & \\
\hline Infection & & & 1 & & & & & & & & & \\
\hline
\end{tabular}

** Fournier's gangrene

partial response, 6 patients $(40 \%, 95$ CI, 16.6-67.7\%) demonstrated stable disease. All of the patients included in this clinical study were heavily pretreated with cytotoxic chemotherapy: six patients had received 3 chemotherapy regimens prior to study treatment and two patients had 4 or more regimens before study treatment. Nearly half of the patients $(n=7)$ had liver metastasis, and one-third $(n=5)$ of patients had peritoneal seeding at the time of study entry. Moreover, one-third of the patients had more than 2 metastatic sites. Importantly, all patients were previously exposed to 5-FU compound-containing regimens including capecitabine/cisplatin, 5-FU/cisplatin, or TS-1/cisplatin.
Given the fact that only $50 \%$ of metastatic gastric cancer patients are able to proceed to second-line chemotherapy $[6,24]$, and disease control rate of $40 \%$ is a promising activity for salvage chemotherapy. At the time of this writing, two patients are still receiving capecitabine/ everolimus. The median duration of tumor response in patients with stable disease was 1.6 months $(95 \% \mathrm{CI}$, 1.1-2.1 months). One patient has achieved stable disease for 6 months. Although the follow-up duration is short, median survival time calculated from the time of study treatment was 4.6 months (95\% CI, 3.9-5.2 months) (Fig. 4). 
Table 4 Adverse events in all cycles

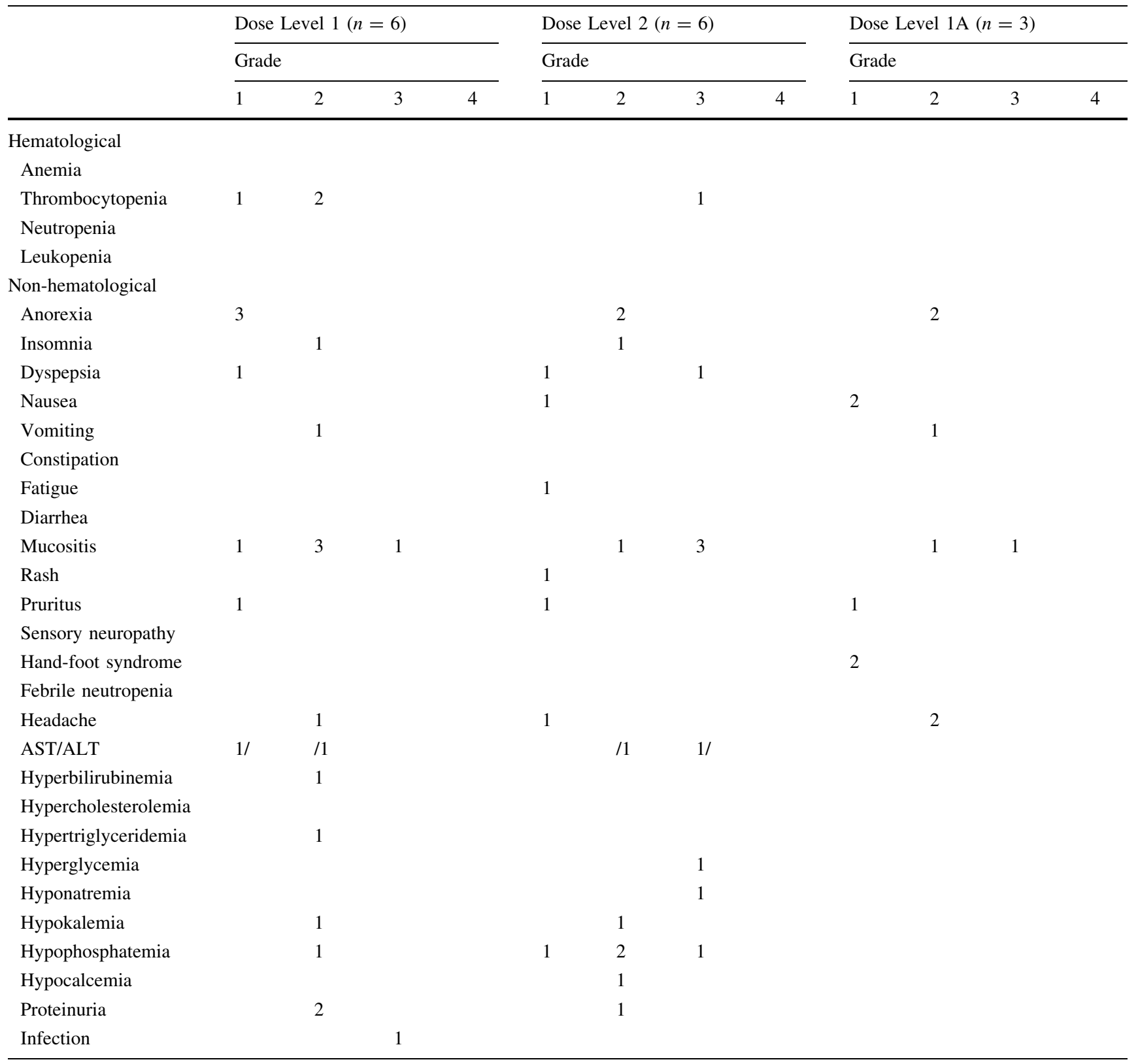

Table 5 Response rate

\begin{tabular}{lllllll}
\hline Dose level & $\begin{array}{l}\text { Number of } \\
\text { patients }\end{array}$ & $\begin{array}{l}\text { Total number } \\
\text { of cycles }\end{array}$ & \multicolumn{2}{l}{ Overall response } \\
\cline { 5 - 6 } & & 11 & CR & PR & SD & PD \\
\hline 1 & 6 & $23+$ & 0 & 0 & 1 & 5 \\
2 & 6 & $9+$ & 0 & 0 & 3 & 3 \\
1 A & 3 & $43++$ & 0 & 0 & 2 & 1 \\
Total & 15 & 0 & 0 & 6 & 9 \\
\hline
\end{tabular}

Recent phase II study has demonstrated a promising antitumor activity of everolimus monotherapy in metastatic gastric cancer with disease control rate of $56.0 \%$ (95\% CI,
41.3-70.0\%) and median PFS of 2.7 months (95\% CI, 6.5-12.1 months) [7]. In this Japanese phase II study, only $8 \%$ had peritoneal seeding and $50 \%$ of patients had only 


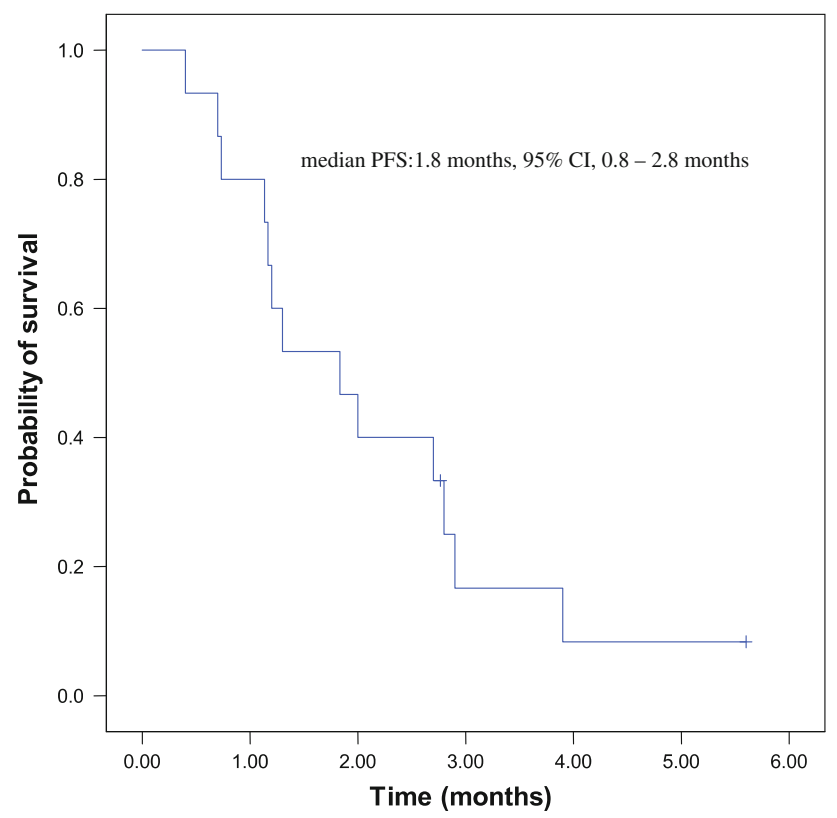

Fig. 1 Kaplan-Meier curve of progression-free survival

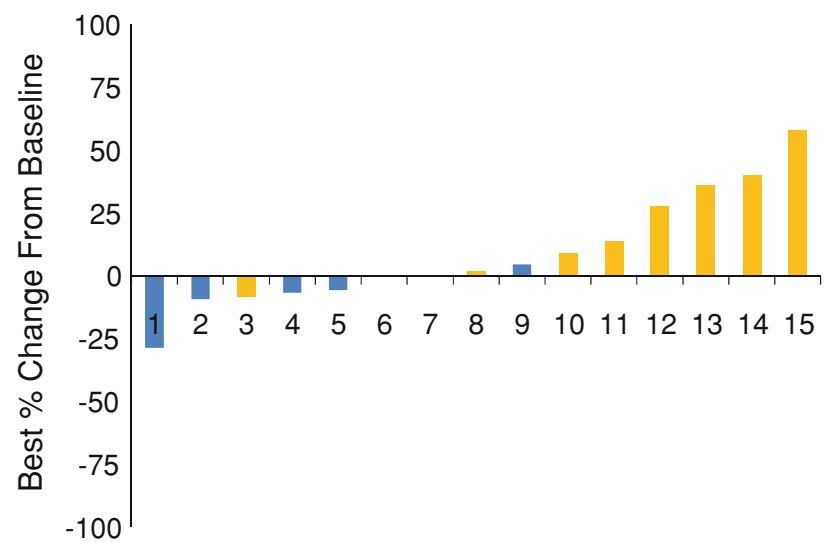

Fig. 2 Maximum best change in tumor size from baseline. Decrease in best percent change from baseline $=28.7 \%$, increase in best percent change or no percent change from baseline $=57.7 \%$. Blue bar stable disease. Yellow bar progressive disease

one previous chemotherapy regimen before everolimus monotherapy. In previous pharmacokinetic study, it has been demonstrated that gastrectomy does not influence the rate of oral absorption of everolimus [7]. Currently, a randomized phase III trial (GRANITE-1) is accruing patients to compare placebo with everolimus $10 \mathrm{mg}$ once daily monotherapy in metastatic gastric cancer patients as second- or third-line treatment. Hence, more efficacy data of everolimus in gastric cancer will become available soon.

This trial represents the first to investigate the safety of a cytotoxic agent with continuous daily dosing schedule of everolimus. Given the convenient administration of two oral drugs and excellent tolerability, capecitabine and

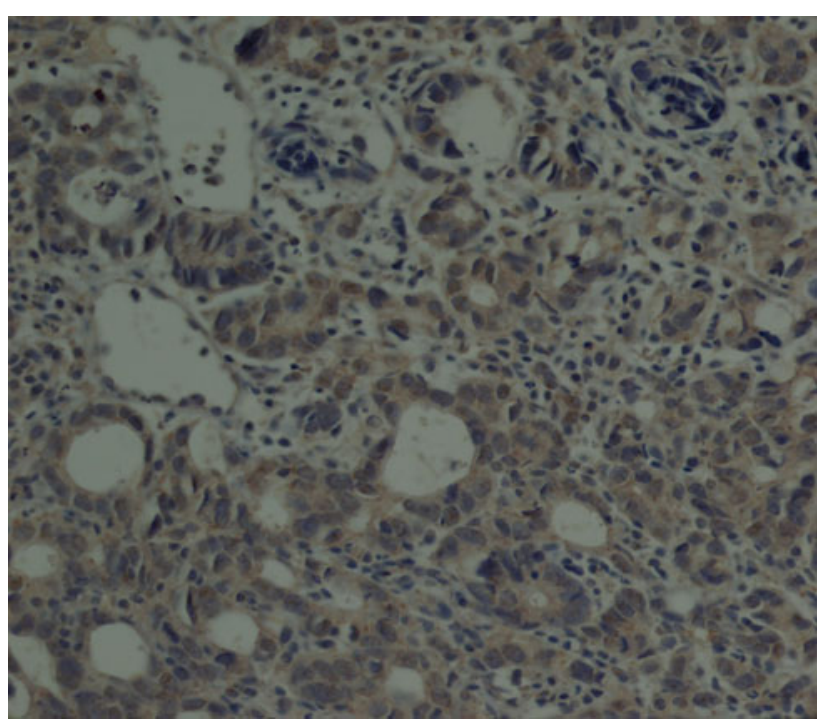

Fig. 3 Positive immunohistochemical staining for phosphor-AKT in the gastric adenocarcinoma tissue specimen $(\times 400)$

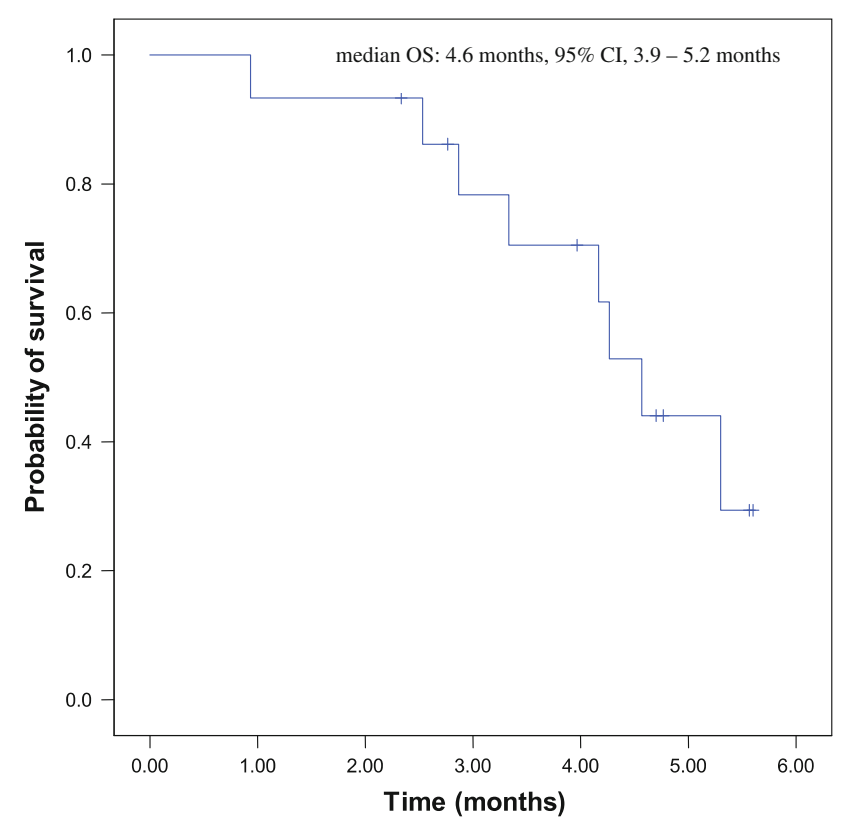

Fig. 4 Kaplan-Meier curve of overall survival

everolimus may be a novel therapeutic option for metastatic gastric cancer patients who have failed the standard 5-FU-based chemotherapy. The recommended dose for subsequent phase II trial is capecitabine $650 \mathrm{mg} / \mathrm{m}^{2}$ twice daily D1-14 and everolimus $5 \mathrm{mg}$ twice daily continuously. We are currently conducting a phase II trial in this clinical setting to investigate the efficacy and toxicity profile of the regimen along with correlative biomarker study. The phase II clinical trial is anticipated to be completed by 2011 .

Conflict of interest None. 
Open Access This article is distributed under the terms of the Creative Commons Attribution Noncommercial License which permits any noncommercial use, distribution, and reproduction in any medium, provided the original author(s) and source are credited.

\section{References}

1. Bae JM, Won YJ, Jung KW, Park JG (2002) Annual report of the korean central cancer registry program 2000. Cancer Res Treat 34:77-83

2. Van Cutsem E, Haller D, Ohtsu A (2002) The role of chemotherapy in the current treatment of gastric cancer. Gastric Cancer 5(Suppl 1):17-22

3. Park SH, Kang WK, Lee HR, Park J, Lee KE, Lee SH, Park JO, Kim K, Kim WS, Chung CW, Im YH, Lee MH, Park CH, Park K (2004) Docetaxel plus cisplatin as second-line therapy in metastatic or recurrent advanced gastric cancer progressing on 5-fluorouracil-based regimen. Am J Clin Oncol 27:477-480

4. Park SH, Choi EY, Bang SM, Cho EK, Lee JH, Shin DB, Ki Lee W, Chung M (2005) Salvage chemotherapy with irinotecan and cisplatin in patients with metastatic gastric cancer failing both 5-fluorouracil and taxanes. Anticancer Drugs 16:621-625

5. Park SH, Kim YS, Hong J, Park J, Nam E, Cho EK, Shin DB, Lee JH, Lee WK, Chung M (2008) Mitomycin C plus S-1 as secondline therapy in patients with advanced gastric cancer: A noncomparative phase II study. Anticancer Drugs 19:303-307

6. Ji SH, Lim do H, Yi SY, Kim HS, Jun HJ, Kim KH, Chang MH, Park MJ, Uhm JE, Lee J, Park SH, Park JO, Park YS, Lim HY, Kang WK (2009) A retrospective analysis of second-line chemotherapy in patients with advanced gastric cancer. BMC Cancer 9:110

7. Doi T, Muro K, Boku N, Yamada Y, Nishina T, Takiuchi H, Komatsu Y, Hamamoto Y, Ohno N, Fujita Y, Robson M, Ohtsu A (2010) Multicenter phase II study of everolimus in patients with previously treated metastatic gastric cancer. J Clin Oncol 28:1904-1910

8. Strimpakos AS, Karapanagiotou EM, Saif MW, Syrigos KN (2009) The role of mTOR in the management of solid tumors: an overview. Cancer Treat Rev 35:148-159

9. Jiang BH, Liu LZ (2008) Role of mTOR in anticancer drug resistance: perspectives for improved drug treatment. Drug Resist Updat 11:63-76

10. Lang SA, Gaumann A, Koehl GE, Seidel U, Bataille F, Klein D, Ellis LM, Bolder U, Hofstaedter F, Schlitt HJ, Geissler EK, Stoeltzing O (2007) Mammalian target of rapamycin is activated in human gastric cancer and serves as a target for therapy in an experimental model. Int J Cancer 120:1803-1810

11. Cunningham D, Okines AF, Ashley S (2010) Capecitabine and oxaliplatin for advanced esophagogastric cancer. N Engl J Med 362:858-859

12. Kang YK, Kang WK, Shin DB, Chen J, Xiong J, Wang J, Lichinitser M, Guan Z, Khasanov R, Zheng L, Philco-Salas M, Suarez T, Santamaria J, Forster G, McCloud PI (2009) Capecitabine/cisplatin versus 5-fluorouracil/cisplatin as first-line therapy in patients with advanced gastric cancer: a randomised phase III noninferiority trial. Ann Oncol 20:666-673

13. Saif MW, Shi N, Zelt S (2009) Capecitabine treatment patterns in patients with gastroesophageal cancer in the United States. World J Gastroenterol 15:4415-4422

14. Bu X, Le C, Jia F, Guo X, Zhang L, Zhang B, Wu M, Wei L (2008) Synergistic effect of mTOR inhibitor rapamycin and fluorouracil in inducing apoptosis and cell senescence in hepatocarcinoma cells. Cancer Biol Ther 7:392-396

15. Therasse P, Arbuck SG, Eisenhauer EA, Wanders J, Kaplan RS, Rubinstein L, Verweij J, Van Glabbeke M, van Oosterom AT, Christian MC, Gwyther SG (2000) New guidelines to evaluate the response to treatment in solid tumors. European Organization for Research and Treatment of Cancer, National Cancer Institute of the United States, National Cancer Institute of Canada. J Natl Cancer Inst 92:205-216

16. Cassidy J, Tabernero J, Twelves C, Brunet R, Butts C, Conroy T, Debraud F, Figer A, Grossmann J, Sawada N, Schoffski P, Sobrero A, Van Cutsem E, Diaz-Rubio E (2004) XELOX (capecitabine plus oxaliplatin): active first-line therapy for patients with metastatic colorectal cancer. J Clin Oncol 22:2084-2091

17. Twelves C, Wong A, Nowacki MP, Abt M, Burris H 3rd, Carrato A, Cassidy J, Cervantes A, Fagerberg J, Georgoulias V, Husseini F, Jodrell D, Koralewski P, Kroning H, Maroun J, Marschner N, McKendrick J, Pawlicki M, Rosso R, Schuller J, Seitz JF, Stabuc B, Tujakowski J, Van Hazel G, Zaluski J, Scheithauer W (2005) Capecitabine as adjuvant treatment for stage III colon cancer. N Engl J Med 352:2696-2704

18. Van Cutsem E, Twelves C, Cassidy J, Allman D, Bajetta E, Boyer M, Bugat R, Findlay M, Frings S, Jahn M, McKendrick J, Osterwalder B, Perez-Manga G, Rosso R, Rougier P, Schmiegel WH, Seitz JF, Thompson P, Vieitez JM, Weitzel C, Harper P (2001) Oral capecitabine compared with intravenous fluorouracil plus leucovorin in patients with metastatic colorectal cancer: results of a large phase III study. J Clin Oncol 19:4097-4106

19. Atkins MB, Hidalgo M, Stadler WM, Logan TF, Dutcher JP, Hudes GR, Park Y, Liou SH, Marshall B, Boni JP, Dukart G, Sherman ML (2004) Randomized phase II study of multiple dose levels of CCI-779, a novel mammalian target of rapamycin kinase inhibitor, in patients with advanced refractory renal cell carcinoma. J Clin Oncol 22:909-918

20. Raymond E, Alexandre J, Faivre S, Vera K, Materman E, Boni J, Leister C, Korth-Bradley J, Hanauske A, Armand JP (2004) Safety and pharmacokinetics of escalated doses of weekly intravenous infusion of CCI-779, a novel mTOR inhibitor, in patients with cancer. J Clin Oncol 22:2336-2347

21. Yee KW, Zeng Z, Konopleva M, Verstovsek S, Ravandi F, Ferrajoli A, Thomas D, Wierda W, Apostolidou E, Albitar M, O'Brien S, Andreeff M, Giles FJ (2006) Phase I/II study of the mammalian target of rapamycin inhibitor everolimus (RAD001) in patients with relapsed or refractory hematologic malignancies. Clin Cancer Res 12:5165-5173

22. Tabernero J, Rojo F, Calvo E, Burris H, Judson I, Hazell K, Martinelli E, Ramon y Cajal S, Jones S, Vidal L, Shand N, Macarulla T, Ramos FJ, Dimitrijevic S, Zoellner U, Tang P, Stumm M, Lane HA, Lebwohl D, Baselga J (2008) Dose- and schedule-dependent inhibition of the mammalian target of rapamycin pathway with everolimus: a phase I tumor pharmacodynamic study in patients with advanced solid tumors. J Clin Oncol 26:1603-1610

23. Soria JC, Shepherd FA, Douillard JY, Wolf J, Giaccone G, Crino L, Cappuzzo F, Sharma S, Gross SH, Dimitrijevic S, Di Scala L, Gardner H, Nogova L, Papadimitrakopoulou V (2009) Efficacy of everolimus (RAD001) in patients with advanced NSCLC previously treated with chemotherapy alone or with chemotherapy and EGFR inhibitors. Ann Oncol 20:1674-1681

24. Lee J, Lim T, Uhm JE, Park KW, Park SH, Lee SC, Park JO, Park YS, Lim HY, Sohn TS, Noh JH, Heo JS, Park CK, Kim S, Kang WK (2007) Prognostic model to predict survival following firstline chemotherapy in patients with metastatic gastric adenocarcinoma. Ann Oncol 18:886-891 